\title{
Carbon Nanotube Composites for Wideband Millimeter-Wave Antenna Applications
}

\author{
Aidin Mehdipour, Member, IEEE, Iosif D. Rosca , Abdel-Razik Sebak, Fellow, IEEE, \\ Christopher W. Trueman, Senior Member, IEEE, and Suong. V. Hoa
}

\begin{abstract}
In this paper, we explore using carbon nanotube (CNT) composite material for wideband millimeter-wave antenna applications. An accurate electromagnetic model of the composite antenna is developed using Microwave Studio for numerical analysis. Good agreement between computed and measured results is shown for both copper and CNT antennas, and their performance is compared. The CNT antenna shows stable gain and radiation patterns over the 24 to $34 \mathrm{GHz}$ frequency range. The dispersion characteristics of the CNT antenna show its suitability for wideband communication systems. Using a quarterwave matched $\mathrm{T}$-junction as feed network, a two-element CNT antenna array is realized and the performance is compared with a copper antenna. The housing effect on the performance of the CNT antenna is shown to be much lower than for the copper antenna.
\end{abstract}

Index Terms - Antenna, carbon nanotube (CNT) composites, millimeter-wave (mm-wave), wideband antenna.

\section{INTRODUCTION}

$\mathrm{M}$ ETALS are commonly used in antenna structures for the radiating elements, feed lines, and ground plane. However, for some applications, cost, fabrication procedure, weight or corrosion resistance can limit the usefulness of metal antennas. Some recent studies have used various composite materials as replacements for metals [1-5]. In [1], a conducting-polymer patch antenna is proposed. Silver nanoparticle ink [2, 3] and metallo-organic conductive ink [4] have been used to prepare a highly-conductive antenna. In [5], metalized foam is used to make microstrip-patch antenna.

Advanced carbon-fiber composite (CFC) materials are being used in the aerospace industry as a replacement for metal $[6,7]$ because of their higher strength, lower cost and lighter weight. There are various kinds of CFCs: reinforced continuous carbon fibers (RCCF) [6], short carbon fibers (SCF), carbon black

Manuscript received $* * * *$. This work was supported in part by the Natural Sciences and Engineering Research Council of Canada (NSERC).

A. Mehdipour was with the Department of Electrical and Computer Engineering, Concordia University, Montreal Quebec, H3G 2W1, Canada. He is now with SDP Telecom Inc., Montreal, QC, Canada H9P 1J1 (e-mail: aidin.mehdipour@sdptelecom.com,a_meh@ece.concordia.ca).

A.-R. Sebak and C. W. Trueman are with the Department of Electrical and Computer Engineering, Concordia University, Montreal Quebec, H3G 2W1, Canada.(email:abdo@ece.concordia.ca,trueman@ece.concordia.ca).

I. D. Rosca and S. V. Hoa are with the Department of Mechanical and Industrial Engineering, Concordia University, Montreal, Quebec, H3G 2W1 Canada, (email: rosca_iosif@yahoo.com, hoasuon@alcor.concordia.ca).
(CB), and carbon nanotube (CNT) [7]. In [8], we investigated the use of carbon fiber materials as radiating elements of an RFID antenna. It was observed that CFC can be efficiently used in such a resonant antenna. Very recently, we explored the use of RCCF for ultra-wideband (UWB) applications [9].

Due to the favorable mechanical and electrical properties, CNTs have been of interest in nanoelectronics and nanoantenna applications [10-17]. The density of CNT composites is around $1.4 \mathrm{~g} / \mathrm{cm}^{3}$, half that of aluminum and more than five times lower than copper. Showing high thermal conductivity of about ten times that of copper, CNTs are attractive for high heat-transfer applications. CNT composites can be made using single-wall nanotubes (SWCNT) or multiwall carbon nanotubes (MWCNT). Details about CNT types and models of materials are given in $[12,13]$. However, CNT dipoles show extremely low efficiency in the order of $10^{-8}$ for microwave applications $[14,15]$, due to their high resistance per unit length, of about $10 \mathrm{k} \Omega / \mu \mathrm{m}$ [14]. Therefore, CNT arrays and composites are proposed to improve the efficiency [17-21]. The electrical conductivity of CNT composites depends on the properties and loading of the CNTs, the aspect ratio of the CNTs, and the characteristics of the conductive network throughout the matrix [7, 22].

Millimeter wave (mm-wave) communication systems are increasingly used in many commercial and military applications, such as imaging systems, automotive radars, medicine, high resolution radars and mobile communication systems $[23,24]$. In mobile and military applications where the antenna may be used in harsh environments, replacing metals with a more suitable material increases the system reliability.

In this work, we have explored the use of SWCNT composite material for wideband mm-wave antennas. A lowprofile wideband microstrip-fed monopole antenna operating over 24 to $34 \mathrm{GHz}$ is designed and investigated by measurement and by numerical simulation. Then, a twoelement array with a matched T-junction feed network is realized and the performance of the CNT antenna is compared with a copper one. Since in reality it is likely that the antenna will be close to other devices or be integrated with different components in the circuit, the housing effect on the copper and CNT antennas performance is investigated.

\section{SWCNT MATERIAL AND METHOD OF COMPOSITE ANTENNA PREPARATION}

The composite samples are produced at the Concordia 


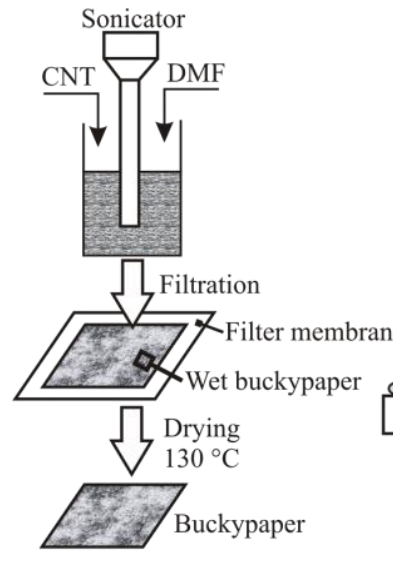

(a)

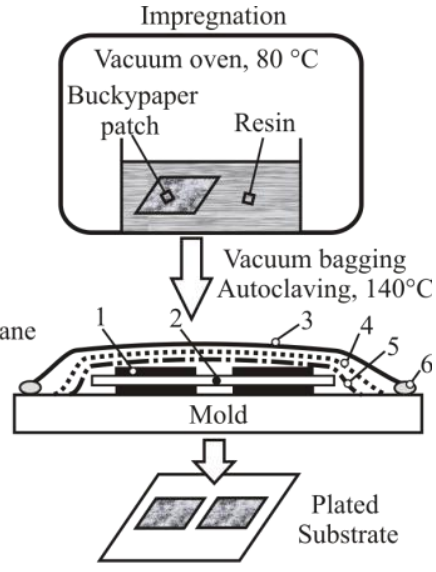

(b)
Fig. 1. (a) Buckypaper preparation, (b) Substrate plating with buckypapers; 1impregnated buckypaper-patch; 2-substrate; 3-vacuum bag; 4-breather; 5release film; 6-sealant.

Center for Composites (CONCOM) [25]. To develop a model of the composite material for use in computer simulations of mm-wave antennas, we use standard Ka-band rectangular waveguide with cross-section dimension of $7.11 \times 3.55 \mathrm{~mm}^{2}$. The thickness of composite is $0.2 \mathrm{~mm}$. Then the waveguide setup is modeled with CST-Microwave Studio (CST MWS) [26]. By minimizing the difference between the simulated and measured scattering parameters over a frequency range, the complex permittivity can be extracted $[9,27]$. The sample used to build the antennas described below has effective relative permittivity $\varepsilon_{r}=5.5$ and conductivity $\sigma=10000 \mathrm{~S} / \mathrm{m}$, over the desired frequency range.

Individual CNTs have outstanding mechanical and electrical properties but the transfer of those properties into the composite is hindered by the difficulties related to their homogenous dispersion and high contact resistances at the nanotube joints [22]. Currently, thin films made of SWCNTs, called buckypapers, display high electrical conductivity [20]. The high conductivity recommends them as an efficient replacement for metals in various electronic applications. For antenna fabrication, we printed CNT on a substrate and then cut out the desired antenna pattern using a high precision milling machine. Buckypaper is a flexible and soft material that needs to be hardened by resin infiltration in order to be processed on a milling machine. Manufacturing buckypaper antennas comprises the following three steps: buckypaper preparation, plating the substrate with buckypaper impregnated with epoxy resin, and cutting out the antenna.

\section{A. Buckypaper preparation}

Buckypaper preparation is schematically shown in Fig. 1(a). SWCNTs from Nikkiso Co. $(0.5 \mathrm{~g})$ are dispersed in N, N dimethylformamide (DMF) by a horn sonicator (Misonix 3000 ) at $42 \mathrm{~W}$ of power for $30 \mathrm{~min}$. Next the SWCNT suspension is filtered on nylon membrane-filter with pore size of 45 micron. After filtration the buckypaper and the membrane are placed between several filter-papers (Whatman no. 1) and lightly pressed between two aluminum plates to absorb the excess solvent. The wet buckypaper is then
TABLE I

RADIATION EFFICIENCY OF THE MONOPOLE ANTENNA AT REF. PLANE 2

\begin{tabular}{|c|c|c|c|c|}
\hline Conductivity $(\mathbf{S} / \mathbf{m})$ & $\mathbf{2 4}$ & $\mathbf{2 8}$ & $\mathbf{3 2}$ & $\mathbf{3 4}$ \\
\hline $5 \times 10^{3}$ & 80.41 & 82.45 & 73.11 & 68.98 \\
\hline $1 \times 10^{4}$ & 84.42 & 85.9 & 81.13 & 76.42 \\
\hline $2 \times 10^{4}$ & 87.76 & 89.19 & 84.49 & 80.54 \\
\hline $3 \times 10^{4}$ & 89.33 & 90.81 & 86.69 & 83.11 \\
\hline $4 \times 10^{4}$ & 90.35 & 91.88 & 88.4 & 84.77 \\
\hline $5 \times 10^{4}$ & 91.1 & 92.63 & 89.53 & 85.98 \\
\hline Copper $\left(5.8 \times 10^{7}\right)$ & 97.74 & 99.2 & 98.8 & 97.11 \\
\hline PEC $(\sigma \rightarrow \infty)$ & 98.01 & 99.51 & 99.02 & 97.47 \\
\hline
\end{tabular}

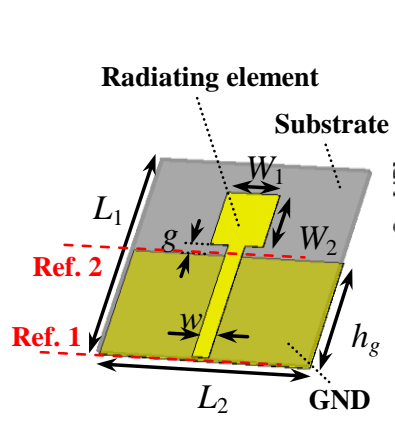

(a)

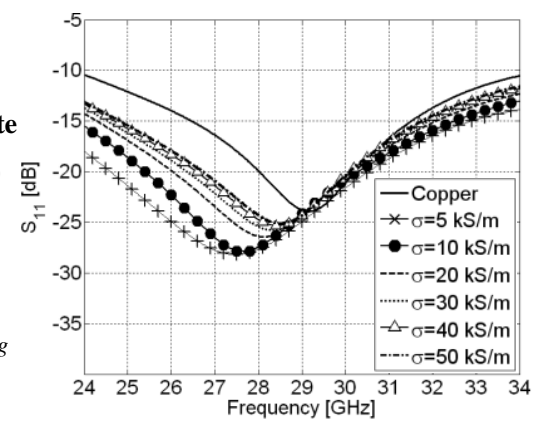

(b)
Fig. 2. (a) The geometry of mm-wave monopole antenna, (b) simulated $S_{11}$ versus conductivity.

separated from the filter membrane and dried at $130^{\circ} \mathrm{C}$ for 12 hours to form a sheet of $140 \times 140 \mathrm{~mm}^{2}$ and $50 \mu \mathrm{m}$ thickness.

\section{B. Substrate plating with buckypaper}

We use Rogers 4350 as the substrate of composite antenna. The copper was removed from the Rogers 4350 substrate by hydrogen peroxide/ hydrochloric acid etching from both sides. Patches of $50 \times 50 \mathrm{~mm}^{2}$ were cut out from a buckypaper sheet. As shown in Fig. 1(b), the patches were impregnated with a mixture of epoxy resin (Epon 862) and hardener (26.4 wt\% Epikure W, Hexion Specialty Chemicals) in a vacuum oven at $80^{\circ} \mathrm{C}$ for $30 \mathrm{~min}$. Next the impregnated patches were placed on each side of the substrate, vacuum-bagged and cured in an autoclave at $140^{\circ} \mathrm{C}$ for 4 hours under $40 \mathrm{psi}$ of pressure. Then, the geometry of antennas is cut out on the substrate using a milling machine.

\section{Single ElEment ANTENNA AND MEASUREMENTS}

Figure 2(a) shows the EM model of monopole antenna developed in MWS. The antenna is fed through a $50-\mathrm{ohm}$ microstrip line. The antenna geometrical parameters are $L_{1}=$ $L_{2}=14 \mathrm{~mm}, W_{1}=3.5 \mathrm{~mm}, W_{2}=3.75 \mathrm{~mm}, g=0.5 \mathrm{~mm}, h_{g}=7.5$ $\mathrm{mm}$, and $w=1.1 \mathrm{~mm}$. The substrate is Rogers 4350 with a thickness of $0.508 \mathrm{~mm}, \varepsilon_{r}=3.48$, and $\tan \delta=0.0037$.

\section{A. Composite Conductivity}

An antenna made of composite is basically a lossy antenna, because the ohmic loss of composite material is higher than that of metal. The impedance bandwidth of a monopole antenna for copper and composites with various conductivities is shown in Fig. 2(b). In the composite antenna both the radiating element and the ground plane are made of CNT. It is observed that the bandwidth of the composite antenna is 


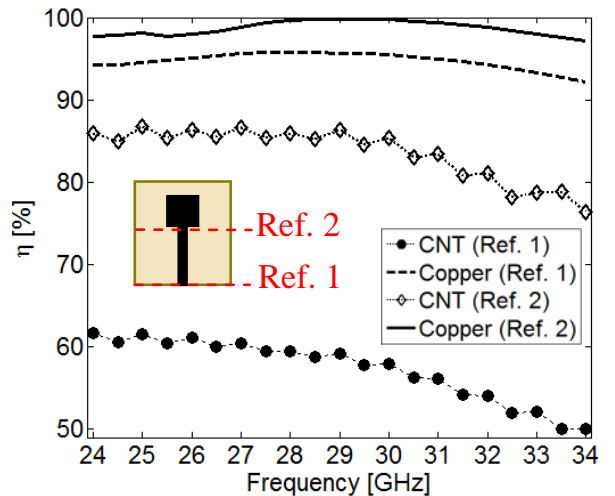

Fig. 3. The radiation efficiency of the copper and CNT $(\sigma=10 \mathrm{kS} / \mathrm{m})$ monopole antennas.

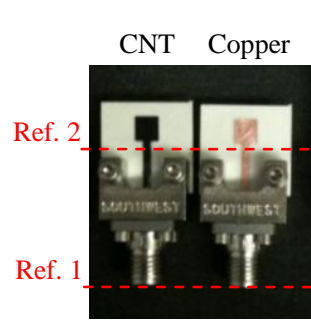

(a)

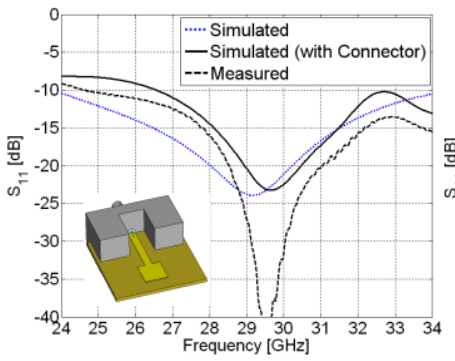

(c)

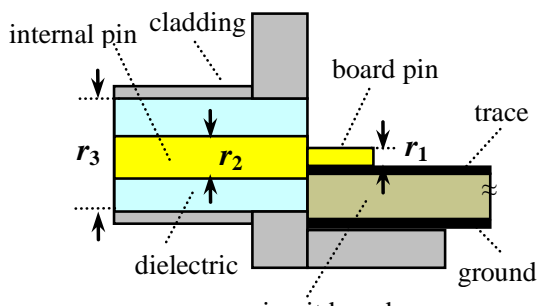

circuit board

(b)

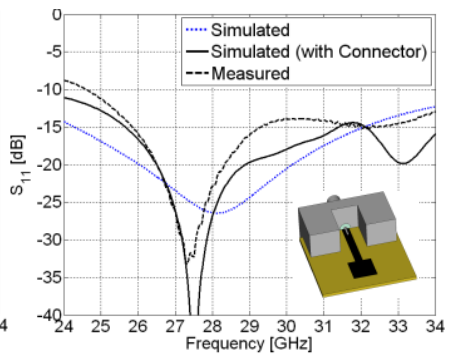

Frequency [GHz]
Fig. 4. (a) Fabricated copper and CNT monopole antennas, (b) connector model $\left(r_{1}=0.18, r_{2}=0.38, r_{3}=1.22 \mathrm{~mm}\right)$, (c) $S_{11}$ of copper antenna, (d) $S_{11}$ of CNT antenna.

wider than that of the copper antenna operating over the 24 to $34 \mathrm{GHz}$ frequency range. In fact, as the ohmic loss increases, the bandwidth increases and the $Q$-factor decreases, and the composite antenna shows this behavior.

Due to the lower conductivity, the gain and radiation efficiency $(\eta)$ of composite antennas are lower than that of the copper antennas. The radiation efficiency is defined as

$$
\eta=\frac{P_{r a d}}{P_{r a d}+P_{l o s s}}
$$

where $P_{\text {rad }}$ and $P_{\text {loss }}$ are the radiated power and the ohmic losses. The overall ohmic loss is the sum of the power loss in the microstrip feed line plus the power loss in the antenna itself. The antenna efficiency in (1) excludes the loss of the feed line, and is calculated at the input of the antenna, reference plane 2. Table I shows the effect of the conductivity on the composite antenna's radiation efficiency at four different frequencies, 24, 28, 32 and $34 \mathrm{GHz}$. Note that using the parameters of the sample described in Section II, $\sigma=10$ $\mathrm{kS} / \mathrm{m}$, the values can be compared with the copper antenna's radiation efficiency.
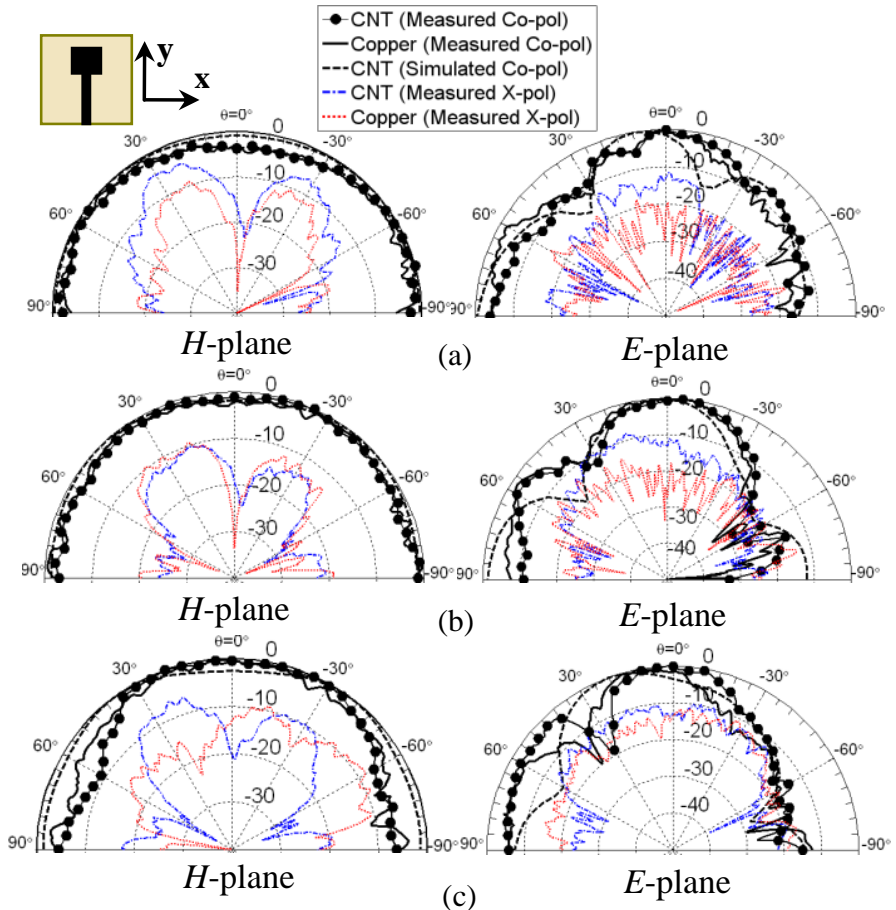

Fig. 5. Normalized radiation pattern of monopole antenna at: (a) $26.5 \mathrm{GHz}$, (b) $29 \mathrm{GHz}$, (c) $33.5 \mathrm{GHz}$.

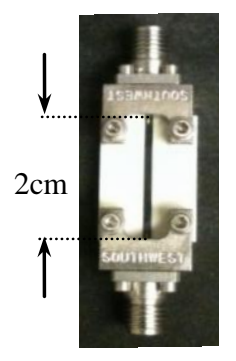

(a)

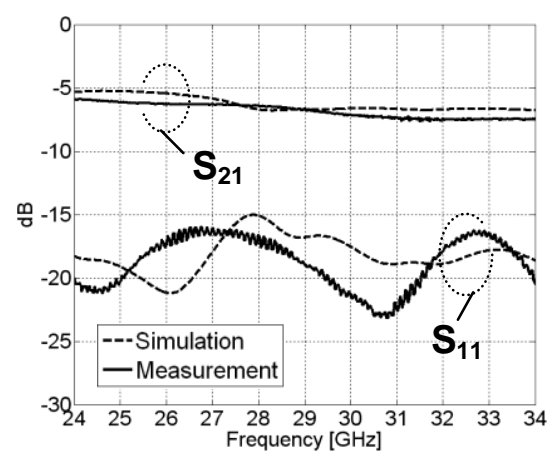

(b)
Fig. 6. (a) Prototype of CNT microstrip line, (b) $S_{11}$ and $S_{21}$ parameters.

Figure 3 shows the radiation efficiency of the copper and CNT antennas, at both reference planes 1 and 2, over the whole frequency range of interest. The curves labeled Ref. 2 give the radiation efficiency of the antenna alone. The curves labeled Ref. 1 give the efficiency of the system made up of the lossy feed line and the antenna, much lower than that of the antenna alone. The lossy feed line behaves as an attenuator, giving control over the amount of power reaching the antenna itself.

\section{B. Experimental Results}

The copper and CNT monopole antennas are fabricated as shown in Fig. 4(a). The composite antenna is fabricated using the method described in Section II. The antennas are fed by solder-free 2.92mm Southwest Microwave connectors [28].

Using an Agilent-E8364B network analyzer, the reflection coefficient of each antenna is measured and shown in Figs. 4(c) and (d). The connector is included in the simulation model in CST-MWS to better simulate the measurement setup. 


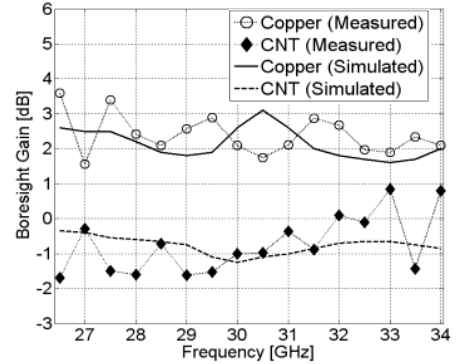

(a)

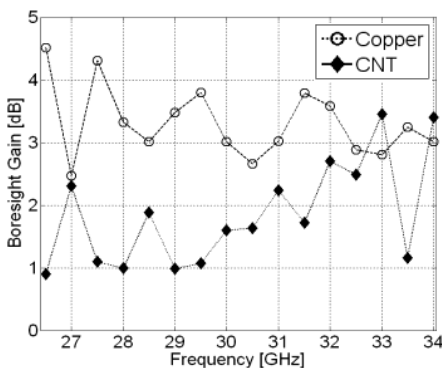

(b)
Fig. 7. Boresight gain of single monopole antenna. (a) measured and simulated gain at Ref. plane 1. (b) measured gain at Ref. plane 2.
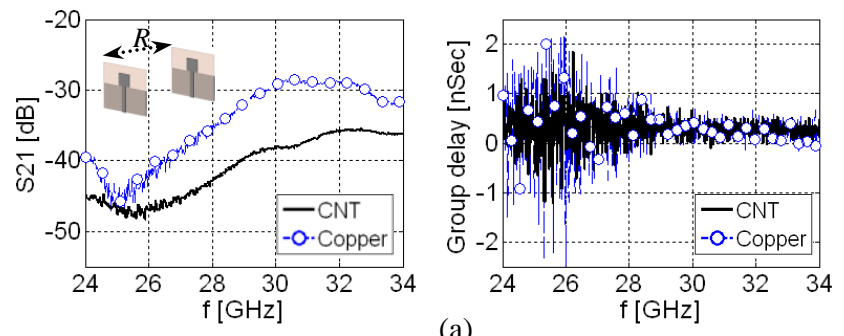

(a)
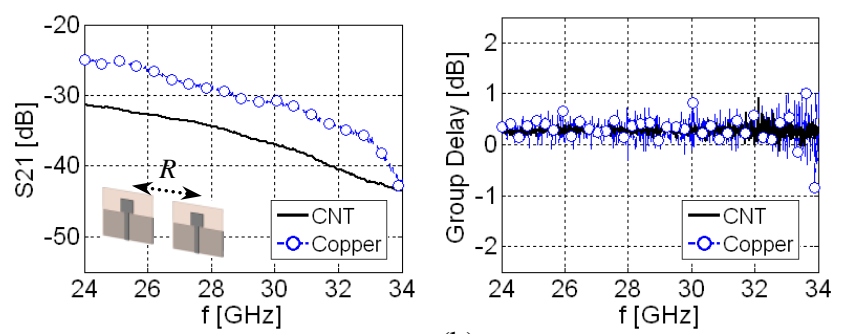

(b)

Fig. 8. Transfer function of monopole antenna in $\mathrm{Tx} / \mathrm{Rx}$ configuration for $R=$ $30 \mathrm{~mm}$, (a) face-to-face, and (b) side-by-side setups.

The radiation pattern of both the copper and the CNT antennas in both the $E-\left(y z_{-}\right)$and the $H$-(xz-) planes were measured in an anechoic chamber. The normalized radiation pattern at 26.5, 29, and $33.5 \mathrm{GHz}$ are reported in Fig. 5. It is observed that the CNT antenna shows a stable radiation pattern over the frequency range of interest. The radiation pattern is found to be almost omnidirectional in the $H$-plane, which is of most interest for wireless communication systems.

It should be noted that the loss associated with the length of the microstrip line can play an important role on the antenna gain. The scattering parameters of a $2 \mathrm{~cm} \mathrm{CNT} \mathrm{microstrip} \mathrm{line}$ were measured and are shown in Fig. 6. After excluding the loss within two connectors $(\sim 1.3 \mathrm{~dB}$ in total), we found that the CNT microstrip line shows about $2.6 \mathrm{~dB} / \mathrm{cm}$ loss over the 24 to $34 \mathrm{GHz}$ frequency range. The loss of copper microstrip line is about $0.35 \mathrm{~dB} / \mathrm{cm}$.

The realized gain at boresight angle $\left(\theta=0^{\circ}, \varphi=90^{\circ}\right)$ in reference plane 1, at the connector in Fig. 4(a), is shown in Fig. 7(a). By excluding the loss of the connector and the microstrip line, the measured antenna gain at reference plane 2, at the input to the radiating element, is shown in Fig 7(b). As expected, it is observed that the average gain of the CNT antenna is lower than the copper one, which is due to the lower conductivity of the composite material.

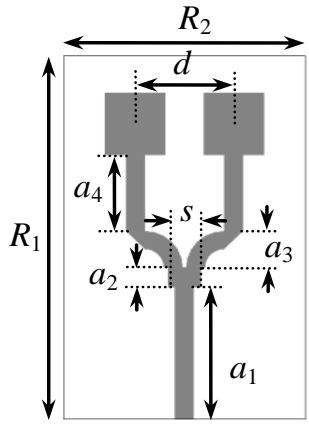

(a)

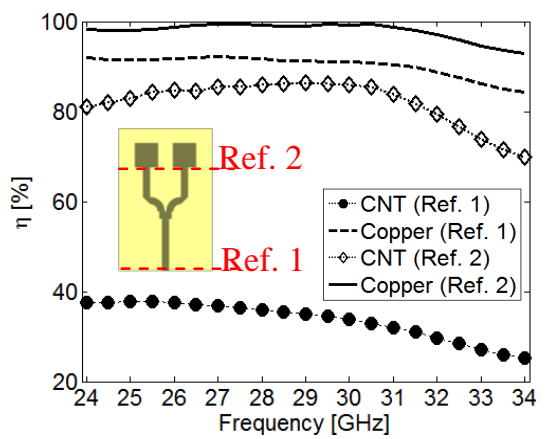

(b)
Fig. 9. (a) The geometry of two-element array antenna. (b) radiation efficiency of the copper and CNT array antennas.

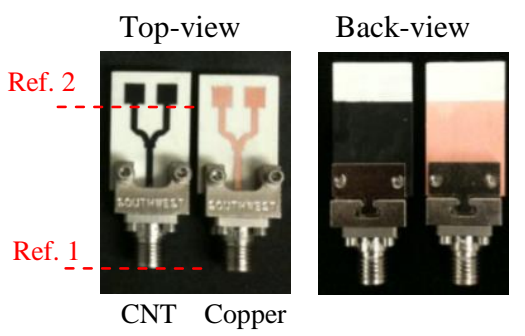

(a)

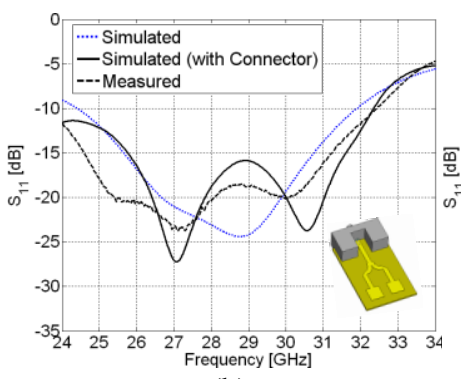

(b)

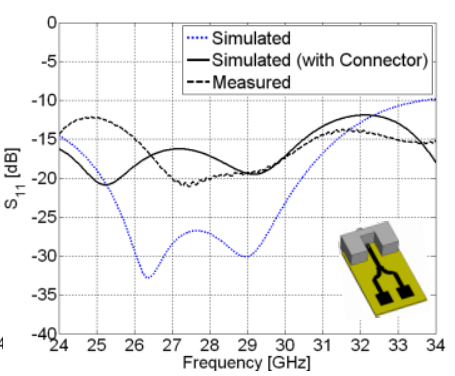

(c)
Fig. 10. (a) fabricated CNT and copper array antenna, (b) $S_{11}$ of the copper antenna, (c) $S_{11}$ of the CNT antenna.

The transfer function of the antenna is measured by making $\mathrm{Tx} / \mathrm{Rx}$ setups of two identical antennas at a separation distance of $R=30 \mathrm{~mm}$. Figure 8 shows the transfer function of CNT and copper antennas for both face-to-face and side-by-side configurations. If the group delay of antennas shows a highly frequency-dependant behavior, the time domain pulse is considerably distorted due to the nonlinearity of phase. But the fairly-constant group delay of Fig. 8 shows that the CNT antenna has low dispersion, indicating that it is useful for UWB radios.

\section{Two-ELEMENT ANTENNA ARRAY AND MEASUREMENTS}

As shown in Fig. 9(a), the two-element array fed by matched T-junction is designed to operate from 24 to $34 \mathrm{GHz}$. The separation distance between elements is $d=5.7 \mathrm{~mm}$ which is about $0.5 \lambda$ at $26.5 \mathrm{GHz}$. The geometrical parameters are $R_{1}=$ 22, $R_{2}=14, a_{1}=8, a_{2}=1.2, a_{3}=2.2, a_{4}=4.6$, and $s=1.9 \mathrm{~mm}$. The ground plane height is $15.5 \mathrm{~mm}$. The radiation efficiency 


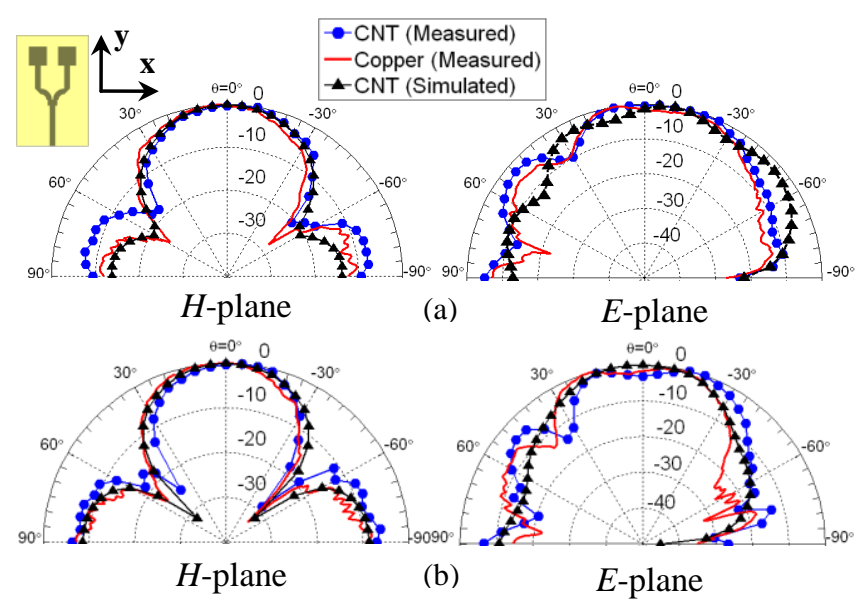

Fig. 11. Normalized radiation pattern of array antenna at: (a) $26.5 \mathrm{GHz}$, (b) $30 \mathrm{GHz}$.

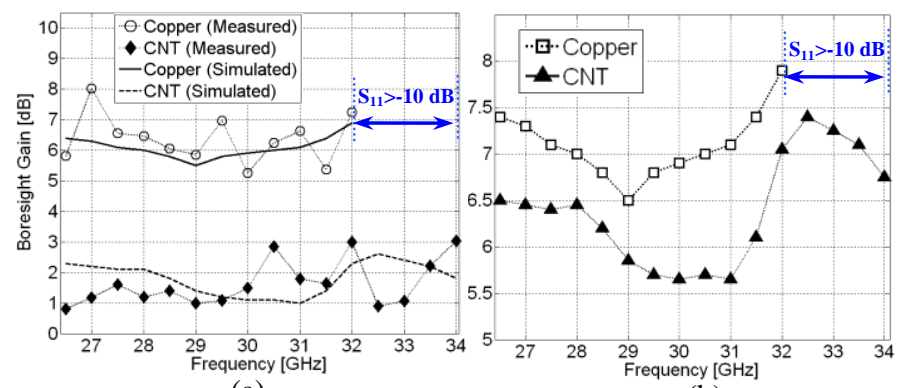

(a)

(b)

Fig. 12. Boresight gain of array antenna, (a) measured and simulated gain at Ref. plane 1. (b) simulated gain at Ref. plane 2 .

of the copper and CNT array antennas is calculated over 24 to $34 \mathrm{GHz}$ frequency range as displayed in Fig. 9(b). The curves labeled Ref. 2 give the radiation efficiency of the antenna alone. The curves labeled Ref. 1 give the efficiency of the system made up of the lossy feed structure plus the antenna. The ohmic loss of the matched T-junction and the feed lines reduces the efficiency of the system greatly compared to the efficiency of the antenna alone.

The copper and CNT array antennas were fabricated and the reflection coefficient $S_{11}$ was measured as shown in Fig.10(c)(d). Good agreement is observed between the measurement and the simulation, specifically when the effect of connectors are considered in EM model of antenna. Due to the bandwidth limitation of the T-junction feed network, the impedance match is degraded at the upper edge of the frequency range for the copper antenna, and the maximum frequency of operation is decreased to $32 \mathrm{GHz}$. An impedance match with $S_{11}<-10$ $\mathrm{dB}$ is desired.

The normalized radiation pattern of the copper and the CNT array antennas was measured and compared at two frequencies, 26.5 and $30 \mathrm{GHz}$, as shown in Fig. 11. It is observed that CNT antenna shows a stable radiation performance over the frequency range of interest.

The gain at the boresight angle in reference plane 1, at the connector in Fig. 10(a), is shown in Fig. 12 (a). Simulations show that the loss of composite T-junction between the

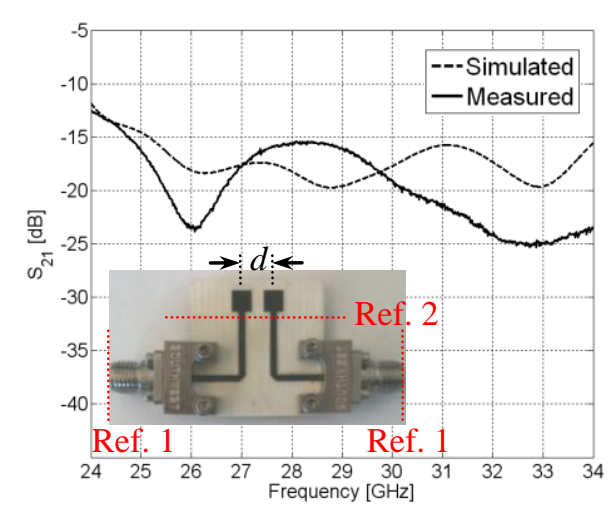

Fig. 13. Mutual coupling of CNT antenna elements at Ref. plane 2.

connector and reference plane 2 is about 3.5-4.4 dB from 24 to $34 \mathrm{GHz}$. Taking out the loss of connector and feed network, the simulated boresight gain of antenna array at reference plane 2 is shown in Fig. 12 (b).

The mutual coupling between the adjacent elements of the array is investigated in Fig. 13. The separation distance between the monopole antennas is $d=5.7 \mathrm{~mm}$. By removing the losses in the microstrip line and the connectors, the mutual coupling between two antennas is obtained at reference plane 2. It is observed that the mutual coupling is lower than $-15 \mathrm{~dB}$ over almost the entire frequency range of interest.

\section{HOUSING EFFECT}

Usually the antenna is integrated in a circuit which includes various components and modules. In mobile and vehicular applications, the antenna could be used in proximity to a variety of materials, such as metal objects or the human body. When the antenna radiates in the vicinity of an object, the backscattered fields produced by the object induce electric current on the antenna, affecting the antenna performance [29, 30]. The induced current on the antenna, $I_{s}$, caused by backscattered magnetic field from nearby scatterer, $H_{\text {scat }}$, can be expressed as,

$$
I_{s} \propto\left(\frac{\eta_{0}}{\eta_{0}+Z_{s}}\right) \cdot H_{s c a t}
$$

where $Z_{s}=(1+j) \sqrt{\pi f \mu_{0} / \sigma}$. Due to the lower conductivity, the composite antenna produces weaker radiated fields than the copper antenna, leading to lower $H_{\text {scat }}$. Moreover, $Z_{s}$ is larger for the composite, making the ratio in (2) lower. As a result, the CNT antenna is less affected by nearby conductive objects than is the copper antenna.

The housing effect setup is shown in Fig. 14(a). A $5 \mathrm{~cm} \times 5$ $\mathrm{cm}$ steel sheet is placed very closely in the front of the antenna with a separation distance of $d$. The reflection coefficient of CNT and copper antennas is measured for $d=2 \mathrm{~mm}$, as displayed in Figs. 14(b) and (c). It is observed that the performance of copper antenna deteriorates significantly, whereas the CNT antenna still operates over the entire frequency range with $S_{11}<-10 \mathrm{~dB}$. We have also investigated the housing effect for different values of $d$, not shown here. It was observed that CNT antenna performance shows much 

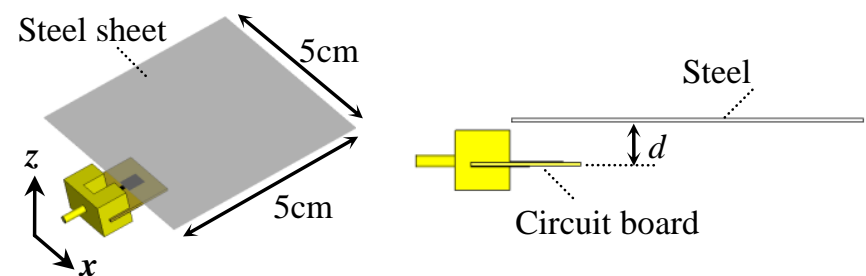

(a)

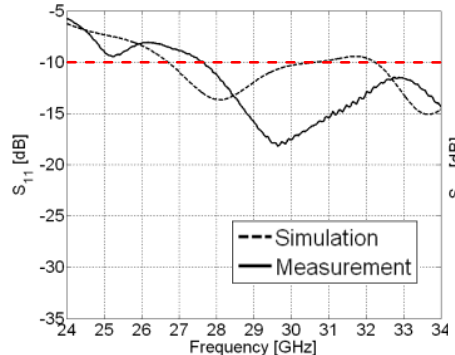

(b)

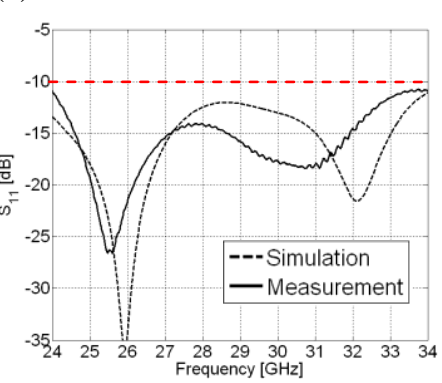

(c)
Fig. 14. (a) Housing effect setup, (b) $S_{11}$ of copper antenna, (c) $S_{11}$ of CNT antenna.

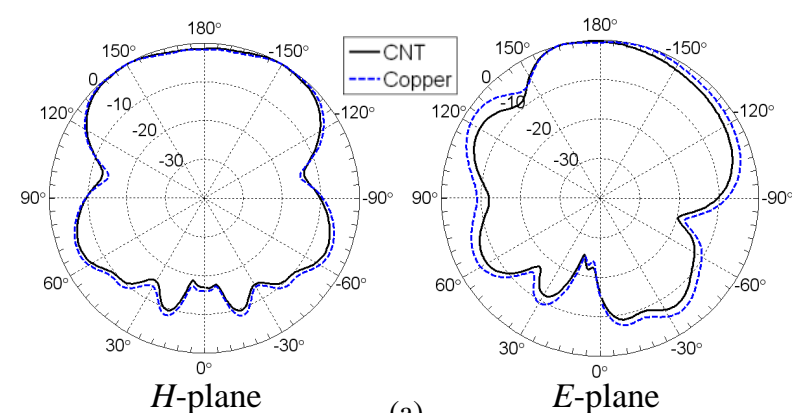

(a)

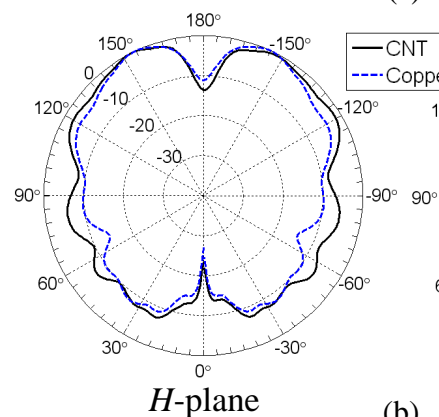

(b)

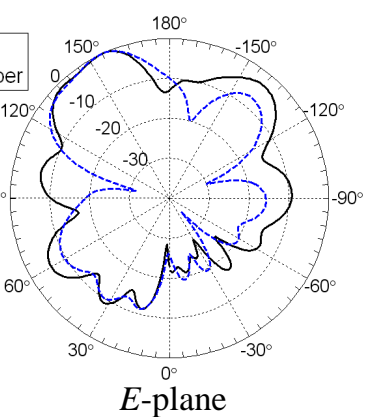

Fig. 15. Normalized radiation pattern in the vicinity of metal sheet at: (a) 25 $\mathrm{GHz}$, (b) $34 \mathrm{GHz}$.

lower sensitivity to the steel sheet than does the copper antenna.

The far-field radiation pattern of the antennas in the vicinity of steel sheet is evaluated as shown in Fig. 15. Since the metal sheet behaves like a good reflector, the main beam of the $E$ plane radiation pattern moves toward $\theta=180^{\circ}$ and the $H$-plane radiation pattern is not omnidirectional anymore. It is observed that as frequency goes up, the number of notches in radiation pattern increases which is due to reflections and diffractions from the metal sheet. However, because of the lower EM coupling with nearby metal sheet, the CNT antenna shows much weaker notches at $E$-plane than copper antenna as shown in Fig. 15(b). We found that the CNT antenna shows
TABLE II

RADIATION EFFICIENCY OF THE COMPOSITE ANTENNA WITH/WITHOUT THE PRESENCE OF METALLIC SHEET

\begin{tabular}{|c|c|c|c|c|c|c|}
\hline $\mathbf{f}(\mathbf{G H z})$ & $\mathbf{2 4}$ & $\mathbf{2 6}$ & $\mathbf{2 8}$ & $\mathbf{3 0}$ & $\mathbf{3 2}$ & $\mathbf{3 4}$ \\
\hline Antenna & 84.4 & 86.3 & 85.9 & 85.3 & 81.1 & 76.4 \\
\hline Antenna+Housing & 82.1 & 80.2 & 79.6 & 81.2 & 79 & 76.8 \\
\hline
\end{tabular}

weaker notches than copper antenna at $E$-plane at frequencies above $30 \mathrm{GHz}$ as well, making the radiation pattern more stable. At lower frequencies, both antennas show almost the same radiation pattern.

The radiation efficiency of the composite antenna at reference plane 2 in the vicinity of metal sheet is calculated as shown in Table II. It is observed that the radiation efficiency of the antenna changes slightly in the presence of the metal sheet. Therefore, since the matching of composite antenna is still good, the total efficiency does not change significantly.

\section{CONCLUSION}

In this paper, a single-wall carbon nanotube composite material is used to fabricate an antenna for millimeter-wave applications. The operation and design guidelines are presented. Measured and simulated results show that the CNT composite antenna has good performance over a bandwidth of 24 to $34 \mathrm{GHz}$. A two-element array antenna shows similar results. Moreover, the CNT antenna shows low dispersion characteristics over the frequency range of interest and so may be used for ultra-wideband radios. The housing effect on the antenna performance is investigated and it is shown that the CNT antenna is much less affected than the copper antenna. The antenna performance such as gain can be adjusted by changing the conductivity of composite, while it is not possible for materials with fixed conductivity such as copper.

\section{REFERENCE}

[1] H. Rmili, J.-L. Miane, H. Zangar, and T. Olinga, "Design of microstripfed proximity-coupled conducting polymer patch antenna," Microw. Opt. Technol. Lett., vol. 48, pp. 655-660, 2006.

[2] L. Yang, A. Rida, R. Vyas, and M. M. Tentzeris, "RFID tag and RF structures on a paper substrate using inkjet-printing technology," IEEE Trans. Microw. Theory Tech., vol. 55, no. 12, pp. 2894-2901, 2007.

[3] P. V. Nikitin, S. Lam, and K. V. S. Rao, "Low cost silver ink RFID tag antennas," in Proc. IEEE Antennas Propag. Society Int. Symp., 2005, pp. 353-356.

[4] S. Ludmerer, "Conductive Inks for RFID Antenna: the low cost high speed route to RFID labels," Parelec. Inc. Available Online: www.parelec.com.

[5] J. Anguera, J.-P. Daniel, C. Borja, J. Mumbru, C. Puente, T. Leduc, N. Laeveren, P. Van Roy, "Metallized foams for fractal-shaped microstrip antennas," IEEE Antennas and Propagat. Mag., vol. 50, no. 6, pp. 2038, 2008.

[6] C. L. Holloway, M. S. Sarto, and M. Johansson, "Analyzing CarbonFiber Composite Materials with Equivalent-Layer Models," IEEE Trans. on Electromagn. Compatibility, vol. 47, no. 4, pp. 833-844, 2005.

[7] I. M. De Rosa, F. Sarasini, M. S. Sarto, and A. Tamburrano, "EMC impact of advanced carbon fiber/carbon nanotube reinforced composites for next-generation aerospace applications," IEEE Trans. Electromagn. Compat., vol. 50, no. 3, pp. 556-563, 2008.

[8] A. Mehdipour, A.-R. Sebak and C. W. Trueman, and S. V. Hoa "Carbon-Fiber composite T-match folded bow-tie antenna for RFID 
applications," Presented in IEEE Antenna and Propagation Symposium (APS 2009), Charleston, SC, June 1-5, 2009.

[9] A. Mehdipour, A.-R. Sebak, C. W. Trueman, I. D. Rosca, and S. V. Hoa, "Reinforced continuous carbon-fiber composites using multi-wall carbon nanotubes for wideband antenna applications," IEEE Trans. on Antenna and Propagat., vol. 58, no. 7, pp. 2451-2456, 2010.

[10] N. Srivastava, H. Li, F. Kreupl, and K. Banerjee, "On the applicability of single-walled carbon nanotubes as VLSI interconnects," IEEE Trans. Nanotechnol., vol. 8, no. 4, pp. 542-559, 2009.

[11] P. Avouris, "Carbon nanotube electronics," Chemical Physics, vol. 281, pp. 429-445, 2002.

[12] G. Y. Slepyan, S. A. Maksimenko, A. Lakhtakia, O. Yevtushenko, A. V. Gusakov, "Electrodynamics of carbon nanotubes: Dynamic conductivity, impedance boundary conditions, and surface wave propagation," Physical Review B, vol. 60, no. 24, pp. 17136-17149, 1999.

[13] G. Y. Slepyan, S. A. Maksimenko, A. Lakhtakia, O. Yevtushenko, "Electromagnetic response of carbon nanotubes and nanotube ropes," Synthetic Metals, vol. 124, pp. 121-123, 2001.

[14] P. J. Burke, S. D. Li, and Z. Yu, "Quantitative theory of nanowire and nanotube antenna performance. IEEE Trans. Nanotechnol., vol. 5, no. 4, pp. 314-334, 2006.

[15] G. W. Hanson, "Fundamental transmitting properties of carbon nanotube antennas," IEEE Trans. on Antenna and Propagat., vol. 53, no. 11 , pp. 3426-3435, 2005.

[16] G. W. Hanson, "Current on an infinitely-long carbon nanotube antenna excited by a gap generator," IEEE Trans. on Antenna and Propagat., vol. 54, no. 1, pp. 76-81, 2006.

[17] C. Rutherglen, and P. Burke, "Nanoelectromagnetics: circuit and electromagnetic properties of carbon nanotubes," Small, vol. 5, no. 8, pp. 884-906, 2009.

[18] J. Song, J. Kim, Y. Yoon, B. Choi, and C. Han, "Inkjet printing of singe-walled carbon nanotubes and electrical characterization of the line pattern," Nanotechnol., vol. 19, no. 9, p. 095702, 2008.

[19] P. J. Burke, and C. Rutherglen, "Carbon nanotube based variable frequency patch antenna”, US patent 2009/0231205 A1, September 17, 2009.

[20] A. Mehdipour, I. D. Rosca, A.-R. Sebak, C. W. Trueman, and S. V. Hoa, "Advanced carbon-fiber composite materials for RFID tag antenna applications", Applied Computational Electromagnetic Society (ACES) Journal, vol. 25, no. 3, pp. 218-229, 2010.

[21] Y. Zhou, Y. Bayram, J. L. Volakis, and L. Dai, "Conformal LoadBearing Polymer-Carbon Nanotube Antennas and RF Front-Ends," IEEE Antenna and Propagation Symposium (APS 2009), Charleston, SC, June 1-5, 2009.

[22] I. D. Rosca, and S. V. Hoa, "Highly conductive multiwall carbon nanotube and epoxy composites produced by three-roll milling," Carbon, vol. 47, pp. 1958-1968, 2009.

[23] M. Sun, Y. P. Zhang, G. X. Zheng, and W-.Y. Yin, "Performance of intra-chip wireless interconnect using on-chip antennas and UWB radios," IEEE Trans. on Antenna and Propagat., vol. 57, no. 9, pp. 2756-2762, 2009.

[24] R. A. Alhalabi, and G. M. Rebeiz, "High-Efficiency angled-dipole antennas for millimeter-wave phased array applications," IEEE Trans. on Antenna and Propagat., vol. 57, no. 10, pp. 2756-2762, 2009.

[25] CONCORDIA CENTER FOR COMPOSITES (CONCOM), Concordia University, QC, Canada, 1979. Online: http://concom.encs.concordia.ca.

[26] CST - Microwave Studio, Computer Simulation Technology, 2009.

[27] R. K. Challa, D. Kajfez, V. Demir, J. R. Gladden, and A. Z. Elsherbeni, "Characterization of multiwalled carbon nanotube (MWCNT) composites in a waveguide of square cross section," IEEE Microwave and Wireless Components Lett., vol. 18, no. 3, pp. 161-163, 2008.

[28] Southwest Microwave, Inc., Tempe, AZ, US.

[29] C.-C. Lin, S.-W. Kuo, and H.-R. Chuang, "A 2.4-GHz printed meanderline antenna for USB WLAN with notebook-PC housing," IEEE Microwave Wireless Components Lett., vol. 15, no. 9, pp. 546-548, 2005

[30] K. Bahadori,, and Y. Rahmat-Samii," "A miniaturized elliptic-card UWB antenna with WLAN band rejection for wireless communications," IEEE Trans. Antennas Propag., vol. 55, no. 11, pp.3326-3332, 2007.

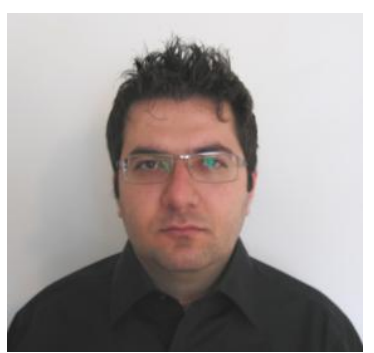

Aidin Mehdipour received the B.S. degree from Amirkabir University of Technology, Tehran, Iran, in 2003, the M.S. degree from the University of Tehran, Tehran, Iran, in 2006, and the Ph.D. degree from Concordia University, Montreal, QC, Canada, in 2011, all in electrical engineering. He is currently a Research Engineer with SDP Telecom Inc., Montreal, QC, Canada. His main research interests include advanced carbon fiber composites electromagnetic analysis, novel material development for shielding and antenna/microwave applications, electromagnetic compatibility (EMC), microwave circuits, small antenna design, RFID, multiband, ultrawideband, and millimeter wave antennas.

He was the recipient of the David J. Azrieli Graduate Fellowship, as the highest ranking Concordia University Fellowship Award, and the France and André Desmarais Graduate Fellowship in 2010, the Howard Webster Foundation Doctoral Fellowship and Doctoral Thesis Completion Award in 2011. He is a member of IEEE AP and EMC societies and of the Applied Computational Electromagnetics Society (ACES).

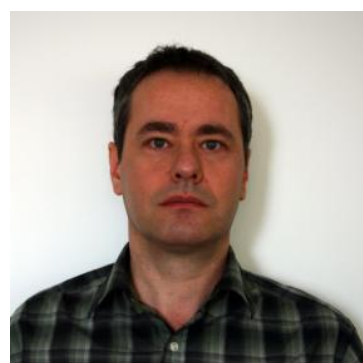

Iosif Daniel Rosca received his engineer diploma in Polymer Science and Technology from Polytechnic University of Bucharest, Romania. He earned his Ph.D. in Chemistry with Prof. J.M. Vergnaud at Jean Monnet University, Saint-Etienne, France. $\mathrm{He}$ is associated professor of Polymer Science and Technology at the Polytechnic University of Bucharest, Romania. Rosca spent 2 years as JSPS Postdoctoral Fellow at Hokkaido University, Japan. He is currently a Research Associate with Prof. S.V. Hoa at Concordia University, Canada. His present research focuses on fabrication and application of polymer composites based on carbon nanomaterials

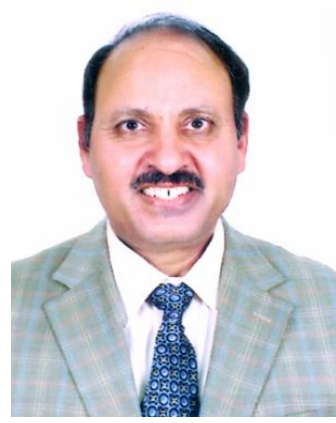

Abdel Razik Sebak received the B.Sc. degree (with honors) in Electrical Engineering from Cairo University, in 1976 and the B.Sc. degree in Applied Mathematics from Ein Shams University, in 1978. He received the M.Eng. and Ph.D. degrees from the University of Manitoba, in 1982 and 1984, respectively, both in electrical engineering.

From 1984 to 1986, he was with the Canadian Marconi Company, working on the design of microstrip phased array antennas. From 1987 to 2002, he was a Professor in the Electrical and Computer Engineering Department, University of Manitoba. $\mathrm{He}$ is a Professor of Electrical and Computer Engineering, Concordia University. His current research interests include phased array antennas, computational electromagnetics, integrated antennas, electromagnetic theory, interaction of EM waves with new materials and bioelectromagnetics.

Dr. Sebak received the 2000 and 1992 University of Manitoba Merit Award for outstanding Teaching and Research, the 1994 Rh Award for Outstanding Contributions to Scholarship and Research, and the 1996 Faculty of Engineering Superior Academic Performance. He is a Fellow of IEEE. Dr. Sebak has served as Chair for the IEEE Canada Awards and Recognition Committee (2002-2004) and the Technical Program Chair of the 2002 IEEECCECE and 2006 ANTEM conferences. 


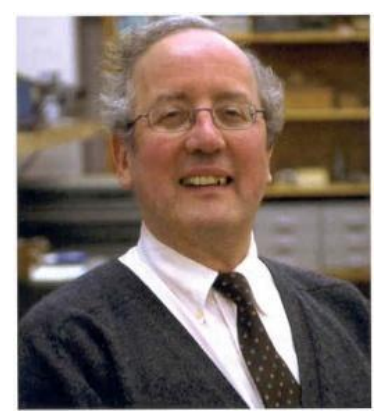

Christopher W. Trueman received his Ph.D. from McGill University in 1979. He has applied the methods of computational electromagnetics to problems such as aircraft antenna performance, antenna-toantenna coupling and EMC on aircraft, aircraft and ship radar cross-section at HF frequencies, suppression of scattering of the signal of a commercial radio station from power lines, dielectric resonators, unconditionally-stable formulations for the finite-difference time-domain method, and the fields of portable radios such as cellular phones held against the head. Recently, his research has investigated the radar cross-section of ships at VHF frequencies, composite materials for aircraft, indoor propagation, and EMC issues between portable radios and medical equipment. Dr. Trueman is currently the Associate Dean for Academic Affairs in the Faculty of Engineering and Computer Science at Concordia University.

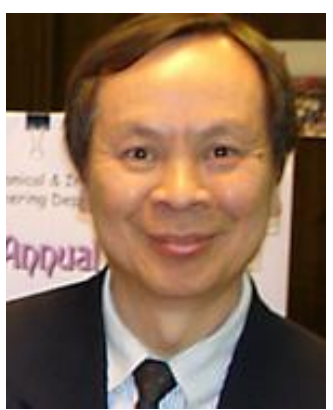

Suong V. Hoa is a professor at the Department of Mechanical and Industrial Engineering at Concordia University, Montreal, Quebec, Canada. He was also Chair of the Department for 9 years from 1994-200 and 2003-2006. He has been working on Composites for the past 31 years (since 1979). He is also President of the Canadian Association for Composite Structures and Materials. He received the Synergy award for collaborative work on composites with Bell Helicopter from the Natural Sciences and Engineering Research Council of Canada in 2006. He also received the Prix partenariat from Association des Directeur de Recherche Industrielle du Quebec in 2006 and in 2009. Dr. Hoa is the recipient of the Nano Academia prize from Nanoquebec in 2008. He was given the title of Research Fellow from Pratt \& Whitney Canada Ltd. in September 2008. He together with Dr. H. Hamada of Kyoto Institute of Technology, initiated the series of Canada-Japan workshop on composites which have been held in Canada and Japan every two years since 1996. 